\title{
Efektivitas Komunikasi Nonverbal Bahasa Isyarat dalam Pemenuhan Kebutuhan Informasi Siswa SLB Cicendo Bandung
}

\author{
Dian Anggraeni Sujati*, Tia Muthiah Umar \\ Fakultas Ilmu Komunikasi, Universitas Islam Bandung, Indonesia. \\ *diananggi230898@gmail.com, tiamutiaumar@gmail.com
}

\begin{abstract}
Nonverbal communication is a symbol used in communication, which is not language but a sign with members of the body, including the head, eyes, lips, hands and fingers. Sign language is usually a combination of form, orientation and gestures of hands, arms, body and facial expressions to express the contents of the mind, therefore sign language is one of the languages needed by persons with hearing impairements to be able to understand and receive messages. Sign language is influenced by the person's cultural background and habits. Sign language is a language whose function is very important fot the deaf in accessing information, so that communication can run effectively if the information conveyed can be understood for deaf students. The effectiveness of communication can be said to be effective if the message delivered by the communicator can produce effects of changes. As for the theory used, the SOR theory (stimulus, organism, response) SOR theory as an abbreviation of Stimulus-Organism-Response was originally derived from pshychology that includes components such as attitudes, opinion, behavior, cognition and conation. This research uses quantitative research methods with a descriptive approach. Using data collectiontehniques in the form of questionnaries and interviews, the population in this study were students of SMA Negeri SLB Cicendo Bandung. Sampling using saturated sampling technique. The results of the study were declaredeffective by fulfilling information needs using sign language interpreters.
\end{abstract}

Keywords: Sign Language, Nonverbal Communication, Communication Effectiveness.

Abstrak. Komunikasi nonverbal adalah lambang yang dipergunakan dalam komunikasi, yang bukan bahasa melainkan selain darinya seperti melainkan isyarat dengan anggota tubuh, antara lain kepala, mata, bibir, tangan, dan jari. Bahasa isyarat biasanya pengkombinasian dari bentuk, orientasi, dan gerak tangan, lengan, tubuh serta ekspresi wajah untuk mengungkapkan isi pikiran oleh karena itu bahasa isyarat merupakan salah satu bahasa yang dibutuhkan oleh penyandang difabel tunarungu agar dapat memahami dan menerima pesan. Bahasa isyarat dipengaruhi oleh latar belakang budaya serta kebiasaan orang tersebut. Bahasa isyarat merupakan bahasa yang fungsinya sangat penting bagi penyandang tunarungu dalam mengakses informasi, sehingga komunikasi dapat berjalan secara efektif jika informasi yang disampaikan dapat dipahami bagi siswa tunarungu. Efektivitas komunikasi dapat dikatakan efektif yaitu apabila pesan yang disampaikan komunikator dapat menghasilkan efek-efek atau perubahan. Berdasarkan keterangan data-data diatas terdapat permasalahan mengenai : "Seberapa efektivitas komunikasi nonverbal bahasa isyarat dalam pemenuhan kebutuhan informasi di Liputan 6 SCTV pada siswa SLB Cicendo Bandung?". Selanjutnya tujuan dalam penelitian ini di uraikan dalam pokok-pokok sebagai berikut: (1) Bagaimana komunikasi nonverbal di liputan 6 terhadap pemenuhan kebutuhan siswa SLB? (2) Bagaimana kualitas komunikasi nonverbal dari liputan 6 terhadap pemenuhan siswa SLB? (3) Bagaimana waktu penayangan kebutuhan komunikasi nonverbal dari liputan 6 terhadap siswa SLB?. Peneliti menggunakan metode penelitian kuantitatif dengan pendekatan deskriptif. Populasi yang dipilih dalam penelitian ini adalah siswa SMA Negeri SLB Cicendo Bandung yang berjumlah 33 siswa. Dengan teknik pengambilan sampel yaitu sampel jenuh diperoleh jumlah sampel penelitian sebanyak 33 siswa. Teknik pengumpulan data yang digunakan dalam penelitian ini adalah kuesioner dan wawancara. Hasil dari penelitian ini adalah: (1) Kualitas Komunikasi Penerjemah Bahasa Isyarat dalam menyampaikan informasi dinyatakan efektif mampu menarik perhatian siswa tunarungu SLB Negeri Cicendo Bandung. (2) Program berita SCTV dinyatakan efektif dalam memberikan informasi kepada siswa tunarungu SLB Negeri Cicendo. (3) Waktu penayangan berita dinyatakan cukup dengan adanya penerjemah bahasa isyarat dalam pemenuhan siswa tunarungu SMA Negeri SLB Cicendo Bandung.

Kata Kunci: Bahasaya isyarat, Komunikasi Nonverbal, Efektivitas Komunikasi. 


\section{A. Pendahuluan}

Setiap manusia berhak untuk memperoleh dan menyampaikan informasi untuk mengembangkan diri dan juga bagi lingkungan sosial disekitarnya dengan menyampaikan informasi dengan menggunakan saluran yang berbeda seperti halnya tatapan muka dalam percakapan, termasuk media sosial seperti radio, televisi, surat kabar.

Komunikasi sangat diperlukan bagi manusia. Karena manusia merupakan mahluk sosial yang membutuhkan interaksi secara langsung maupun tidak langsung dalam menjalankan kehidupan sehari-hari. Oleh karena itu komunikasi menjadi suatu komponen penting bagi manusia.

Semua manusia pasti memerlukan kemampuan komunikasi dengan baik dan lancar. Agar pesan yang disampaikan dapat diterima dan dipahami oleh penerima pesan. Komunikasi menurut sifatnya dibagi menjadi dua macam yaitu komunikasi verbal dan komunikasi nonverbal.

Komunikasi nonverbal mencakup semua rangsangan (kecuali rangsangan verbal) dalam suatu setting komunikasi, yang dihasilkan oleh individu dan penggunaan lingkungan oleh individu, yang mempunyai nilai pesan potensial bagi pengirim atau penerima.

Berdasarkan pengertian diatas komunikasi nonverbal dilakukan dengan cara seseorang dalam mengucapkan lambang-lambang verbal yang termasuk ke dalam unsur paralingusitik. Seperti halnya dilakukan dengan mengirimkan pesan dengan menggunakan isyarat, gerakan tubuh, untuk menggambarkan situasi yang sedang terjadi.

Berdasarkan keterangan data-data diatas terdapat permasalahan mengenai : "Seberapa efektivitas komunikasi nonverbal bahasa isyarat dalam pemenuhan kebutuhan informasi di Liputan 6 SCTV pada siswa SLB Cicendo Bandung?". Selanjutnya, tujuan dalam penelitian ini diuraikan dalam pokok-pokok sbb.

1. Untuk mengetahui komunikasi nonverbal di liputan 6 terhadap pemenuhan kebutuhan siswa SLB.

2. Untuk mengetahui kualitas komunikasi nonverbal dari liputan 6 terhadap pemenuhan siswa SLB.

3. Untuk mengetahui waktu penayangan kebutuhan komunikasi nonverbal dari liputan 6 terhadap siswa SLB.

\section{B. Landasan Teori}

Menurut Bittner (1980), Komunikasi massa merujuk pada proses komunikasi dimana pesanpesan yang disampakan melalui media massa pada sejumlah besar orang. Media Massa dapat berupa media massa cetak seperti surat kabar, majalah, dan buku, serta media elektronik seperti radio dan televisi dan media digital yaitu internet.

Efektivitas Komunikasi dapat dikatakan efektif yaitu apabila pesan yang disampaikan komunikator dapat menghasilkan efek-efek atau perubahan sebagaimana yang sesuai keinginan komunikator, seperti perubahan pengetahuan, sikap dan perilaku.

Menurut Larry A. Samovar dan Richard E. Porter, (2005), "Komunikasi nonverbal mencakup semua rangsangan (kecuali rangsangan verbal) dalam suatu setting komunikasi yang dihasilkan oleh individu dan penggunaan lingkungan oleh individu, yang mempunyai nilai pesan potensial bagi pengirim atau penerima."

Penerjemah Bahasa Isyarat (Interpreter) yaitu seorang penerjemah yang menerjemahkan bahasa dengan gerakan badan seperti gerakan tangan, lengan tubuh dan ekspresi wajah dari makna bahasa lisan tersebut, agar para kaum tunarungu cukup paham. Bahasa isyarat masuk ke dalam kelompok komunikasi nonverbal dan nonvocal dimana penyampaian pesan atau informasi tidak memberikan suara tetapi memberikan isyarat dengan tangan, gerakan tubuh, penampilan serta ekspresi wajah, isyarat tangan kadang kadang menggantikan komunikasi verbal. Seorang juru Bahasa isyarat (interpreter) akan dinilai berhasil jika dapat menyampaikan pesanberita dan informasi kepada penyandang disabilitas tunarungu dengan baik, effektif. (Tubs dan Moss, $2005: 22$ ) 


\section{Hasil dan Pembahasan}

Setelah melakukan pengolahan informasi berdasarkan dari hasil wawancara yang dilakukan Wakil Kepala Sekolah, siswa penyandang tunarungu. Penulis mendapatkan hasil mengenai efektivitas komunikasi nonverbal bahasa isyarat dalam pemenuhan kebutuhan informasi siswa SLB Cicendo Bandung.

Mengenai hasil temuan dan analisis data yang telah dikumpulkan dan diolah oleh peneliti, yaitu kualitas komunikasi penerjemah bahasa isyarat tidak ada responden yang menjawab sangat tidak setuju, artinya sebagian besar siswa tunarungu di SMA Negeri SLB Cicendo Bandung menyetujui bahwa kualitas komunikasi penerjemah bahasa isyarat di Liputan 6 SCTV memenuhi kebutuhan responden. Perolehan jawaban tertinggi dengan tanggapan setuju sebanyak 12 orang dengan jumlah persentase 36,36\% menunjukkan pemahaman responden terhadap isi berita di Liputan 6 SCTV dengan menggunakan Bahasa Isyarat Indonesia (BISINDO) untuk memenuhi kebutuhan siswa tunarungu SLB Cicendo.

Hasil responden terbanyak yang menjawab setuju sebanyak 12 orang dengan persentase $36,36 \%$ menunjukan bahwa waktu penayangan berita cukup dengan adanya penerjemah bahasa isyarat dalam pemenuhan siswa tunarungu SMA Negeri SLB Cicendo Bandung.

Hasil jawaban angket siswa SLB Cicendo Bandung sejalan dengan pernyataan diatas yang menyatakan bahwa komunikasi penerjemah membantu dan memenuhi kebutuhan siswa dalam mempelajari bahasa isyarat dan menambah kosakata isyarat. Dalam prosesnya peneliti mengumpulkan data primer melalui teknik pengumpulan data kuesioner. Kuesioner disebar kepada 33 orang siswa SMA Negeri SLB Cicendo Bandung. Jumlah pertanyaan dalam kuesioner adalah 15 butir pertanyaan, terdiri dari 1 pertanyaan data responden dan 14 pertanyaan penelitian.

Hal ini sejalan dengan apa yang disampaikan menurut penerjemah, Ibu Dinda bahwa kualitas media dalam menggunakan translasi bahasa isyarat dalam program berita di Liputan 6 SCTV sudah baik, dalam rangka memfasilitas penyandang disabilitas tunarungu, sesuai dengan hasil data kuesioner sebagian siswa tunarungu di SMA Negeri SLB Cicendo Bandung menyetujui bahwa kualitas komunikasi penerjemah bahasa isyarat di Liputan 6 SCTV memenuhi kebutuhan responden.

Tabel 3.1 Kebutuhan Informasi

\begin{tabular}{|c|c|c|c|c|c|c|c|c|c|c|}
\hline $\begin{array}{l}\text { Ite } \\
\text { m }\end{array}$ & Bobot & 5 & 4 & 3 & 2 & 1 & Skor Aktual & Skor Ideal & $\%$ & Kategori \\
\hline \multirow{2}{*}{7} & Frekuensi & 5 & 22 & 6 & 0 & 0 & \multirow{2}{*}{131} & \multirow{2}{*}{165} & \multirow{2}{*}{79,39} & \multirow{2}{*}{ Efektif } \\
\hline & Total & 25 & 88 & 18 & 0 & 0 & & & & \\
\hline \multirow{2}{*}{8} & Frekuensi & 9 & 18 & 2 & 3 & 1 & \multirow[b]{2}{*}{130} & \multirow[b]{2}{*}{165} & \multirow{2}{*}{78,79} & \multirow[b]{2}{*}{ Efektif } \\
\hline & & & & & & & & & & \\
\hline & & & & & & & & & & \\
\hline \multirow{3}{*}{9} & Frekuensi & 5 & 12 & 7 & 6 & 3 & \multirow{3}{*}{109} & \multirow{3}{*}{165} & \multirow{3}{*}{6606} & \multirow{3}{*}{ Efektif } \\
\hline & & & & & & & & & & \\
\hline & Total & 25 & 48 & 21 & 12 & 3 & & & & \\
\hline \multirow{3}{*}{10} & Frekuensi & 11 & 13 & 7 & 2 & 0 & \multirow{3}{*}{132} & \multirow{3}{*}{165} & \multirow{3}{*}{80,00} & \multirow{3}{*}{ Sangat Efektif } \\
\hline & & & & & & & & & & \\
\hline & Total & 55 & 52 & 21 & 4 & 0 & & & & \\
\hline \multicolumn{7}{|c|}{ Total } & 502 & 660 & 76,06 & Efektif \\
\hline
\end{tabular}

Dengan jumlah responden sebanyak 33 orang dan bobot nilai 5 maka skor ideal yang bias didapatkan oleh setiap item adalah sebesar 165. Berdasarkan tabel 5.4. kebutuhan informasi total hasil skor aktual sebesar 502, dan total skor ideal 660 dengan jumlah total persentase $76,06 \%$. Hasil pengklasifikasian presentase tanggapan responden dinyatakan efektif. 
Tabel 3.2 Efektivitas pemenuhan kebutuhan informasi melalui berita liputan 6

\begin{tabular}{|c|c|c|c|c|c|c|c|c|c|c|}
\hline Item & Bobot & 5 & 4 & 3 & 2 & 1 & Skor Aktual & Skor Ideal & $\%$ & Kategori \\
\hline \multirow{2}{*}{1} & Frekuensi & 18 & 9 & 4 & 2 & 0 & \multirow{2}{*}{142} & \multirow{2}{*}{165} & \multirow{2}{*}{86,06} & \multirow[t]{2}{*}{ Sangat } \\
\hline & Total & 90 & 36 & 12 & 4 & 0 & & & & \\
\hline \multirow{3}{*}{2} & Frekuensi & 4 & 9 & 9 & 9 & 2 & \multirow{3}{*}{103} & \multirow{3}{*}{165} & \multirow{3}{*}{62,42} & \multirow{3}{*}{ Efektif } \\
\hline & & & & & & & & & & \\
\hline & Total & 20 & 36 & 27 & 18 & 2 & & & & \\
\hline \multirow{2}{*}{3} & Frekuensi & 12 & 16 & 4 & 1 & 0 & \multirow{2}{*}{138} & \multirow{2}{*}{165} & \multirow{2}{*}{83,64} & \multirow[t]{2}{*}{ Sangat } \\
\hline & Total & 60 & 64 & 12 & 2 & 0 & & & & \\
\hline \multirow{3}{*}{4} & Frekuensi & 4 & 14 & 12 & 3 & 0 & \multirow{3}{*}{118} & \multirow{3}{*}{165} & \multirow{3}{*}{71,52} & \multirow{3}{*}{ Efektif } \\
\hline & & & & & & & & & & \\
\hline & Total & 20 & 56 & 36 & 6 & 0 & & & & \\
\hline \multirow{3}{*}{5} & Frekuensi & 6 & 12 & 7 & 8 & 0 & \multirow{3}{*}{115} & \multirow{3}{*}{165} & \multirow{3}{*}{69,70} & \multirow{3}{*}{ Efektif } \\
\hline & & & & & & & & & & \\
\hline & Total & 30 & 48 & 21 & 16 & 0 & & & & \\
\hline \multirow{2}{*}{6} & Frekuensi & 13 & 16 & 4 & 0 & 0 & \multirow{2}{*}{141} & \multirow{2}{*}{165} & \multirow{2}{*}{85,45} & \multirow[t]{2}{*}{ Sangat } \\
\hline & Total & 65 & 64 & 12 & 0 & 0 & & & & \\
\hline \multicolumn{7}{|c|}{ Total } & 757 & 990 & 76,46 & Efektif \\
\hline
\end{tabular}

Dengan jumlah responden sebanyak 33 orang dan bobot nilai 5 maka skor ideal yang biasa didapatkan oleh setiap item adalah sebesar 165. Berdasarkan tabel 5.3. efektivitas pemenuhan kebutuhan informasi berita melalui berita liputan 6 deengan total hasil skor aktual sebesar 757, dan total skor ideal 990 dengan jumlah total persentase 76,46\%. Hasil pengklasifikasian presentase tanggapan responden dinyatakan efektif.

Berdasarkan perolehan data dari hasil penyebaran angket pada 33 siswa SMA Negeri SLB Cicendo Bandung, varibel (X) dan variabel $(\mathrm{Y})$ dinyatakan efektif dikarenakan hasil total persentase kebutuhan informasi lebih tinggi dan responden tertarik menonton berita di Liputan 6 SCTV dengan menggunakan interpreter bahasa isyarat, dan kualitas dalam pemenuhan kebutuhan informasi terpenuhi dan sesuai dengan kebutuhan responden.

Selanjutnya hasil temuan yang telah di dapat berdasarkan pertanyaan penelitian yang sudah diturunkan menjadi sebuah model. Berikut adalah modelnya: 


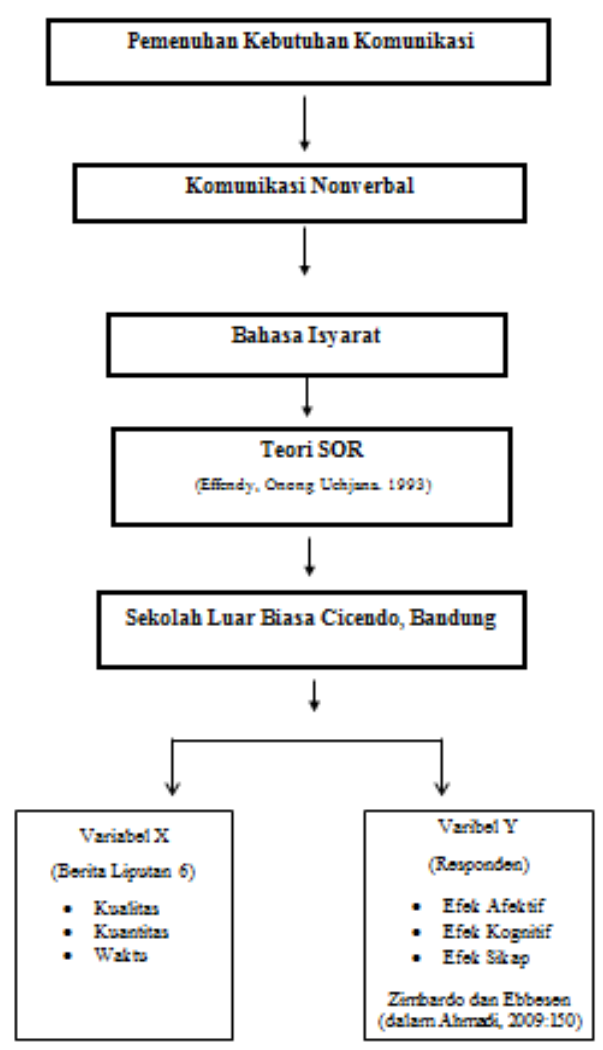

Gambar 3.1. Kerangka Pemikiran

\section{Kesimpulan}

Berdasarkan pembahasan dalam penelitian ini, peneliti menyimpulkan beberapa hasil penelitian sebagai berikut:

1. Kualitas Komunikasi Penerjemah Bahasa Isyarat dalam menyampaikan informasi memperoleh, tanggapan responden tertinggi dari kuesioner penelitian ini dengan menjawab setuju, dengan jumlah frekuensi yaitu 18 orang, dan jumlah persentase sebesar $54,55 \%$ merupakan nilai efektif mampu menarik perhatian siswa tunarung dari SLB Negeri Cicendo Bandung.

2. Program berita SCTV dalam memberikan informasi kepada siswa tunarungu SLB Negeri Cicendo mendapat tanggapan setuju pada kuesioner penelitian ini dengan persentase tertinggi yaitu dengan jumlah 16 responden dengan jumlah persentase $48,48 \%$, bahwa mereka setuju program berita SCTV efektif dapat memberikan informasi kepada siswa tunarungu dari SLB Negeri Cicendo Bandung.

3. Waktu penayangan berita dalam memberikan informasi kepada siswa tunarungu hasil responden terbanyak yang menjawab setuju dengan sebanyak 12 orang dengan persentase 36,36\% menunjukan bahwa responden setuju pada waktu penayangan berita cukup dengan adanya penerjemah bahasa isyarat dalam pemenuhan siswa tunarungu SMA Negeri SLB Cicendo Bandung. 


\section{Daftar Pustaka}

[1] Samovar, L., Porter, Richard. dan McDaniel, Edwin R. 2010. Komunikasi Lintas Budaya. Jakarta: Salemba Humanika

[2] Bittner. 1980. Mass Communication an Introduction Engelwood Cliffs. New Jersey.

[3] Tubbs, Stewart L \& Sylvia Moss. 2005. Human Communication: Konteks-Konteks Komunikasi. Editor Deddy Mulyana. Bandung : Remaja Rosdakarya

[4] Mulyana, Deddy. 2005. Ilmu Komunikasi Suatu Pengantar. Bandung: PT. Remaja Rosdakarya 